\title{
OBSERVAÇÕES SOBRE OS NIVEIS GLICEMICOS DE HOLOCHILUS BRASILIENSIS NANUS THOMAS, 1897, HOSPEDEIRO NATURAL DO SCHISTOSOMA MANSONI NA PRÉ-AMAZÔNIA*
}

\author{
Othon de Carvalho Bastos** \\ Grace Mary Jorge Pires Leal** \\ Bernardete Jorge Leal Salgado**
}

\begin{abstract}
BASTOS, $O$. de $C$. et al. Observações sobre os níveis glicêmicos de Holochilus brasilien. sis nanus Thomas, 1897, hospedeiro natural do Schistosoma mansoni na Pré-Amazônia. Rev. Saúde públ., S. Paulo, 19:521-30, 1985.
\end{abstract}

RESUMO: Roedores silvestres, nascidos em biotério, descendentes de Holochilus b. nanus, capturados na região da Baixada Maranhense, localizada na Pré-Amazônia, foram infectados experimentalmente com Schistosoma mansoni, procedente da mesma Região, com o objetivo de verificar a influência da infecção sobre os níveis glicêmicos. Um grupo de roedores não infectados tiveram, também, seus níveis glicêmicos determinados, para o conhecimento da concentração normal de glicose. $\mathbf{O}$ estudo procedeu distinguindo os animais, tanto os normais quanto os infectados, por sexo, regime alimentar e idade de infecção. A quantificação da glicose sérica foi feita pelo método da Orto-Toluidina, após sangrias semanais pelo plexo oftálmico, sempre no mesmo horário. Os resultados mostraram que ocorreu elevação de pesos corporais de todos os animais normais, durante suas maturações, ao passo que, os animais infectados, tiveram seus pesos em decréscimo, durante a evolução da infecção. Os níveis glicêmicos estudados nos animais normais mostraram que as fêmeas possuem nível mais baixo e estável do que os machos, independente de terem sido alimentados ou não. Os animais infectados aos 30 dias de vida tiveram seus níveis glicêmicos em declínio à proporção que a infecção evoluía, provavelmente, devido ao acometimento dos órgãos, como baço, fígado e pâncreas; enquanto que, os animais infectados aos 40 dias de vida, tiveram seus níveis de glicose, durante as 8 semanas de infecção, sem diferença significativa entre eles. O número de vermes adultos recuperados nos animais infectados com 30 dias de vida foi maior do que o número encontrado nos roedores do outro grupo. Os dados informaram, também, que, a idade ideal para a infecção deste novo modelo experimental, deva ser a de 30 dias de vida, semelhante a outros, como camundongos.

UNITERMOS: Holochilus brasiliensis nanus, infecção experimental. Schistosoma mansoni. Glicose no sangue, análise.

\section{INTRODUÇÃO}

A esquistossomose mansônica, dentre as endemias parasitárias brasileiras, é a que atinge um dos mais altos índices da população. A vasta distribuição geográfica deste país e suas diversidades por regiões, dificulta a aplicação de medidas profiláticas adequadas, fazendo com que esta parasitose se torne em problema de natureza médico-sócio-econômico para as autoridades de saúde pública?

No Maranhão, a presença desta parasitose é conhecida desde $1920^{1}$; com um foco no litoral e dois outros, um pouco mais para o interior ${ }^{10}$. Hoje, esta doença apresenta caráter endêmico, principalmente na região da Baixada (SUCAMMA), onde são encontradas localidades com altas prevalências, tanto em homens

\footnotetext{
- Trabalho financiado pelo Conselho Nacional de Desenvolvimento Científico e Tecnológico (CNPq), Processo n. 403815/ 82, com o apoio da Superintendência de Campanhas de Saúde Pública (SUCAM).

* Do Programa de Pesquisa e Pós-Graduação em Imunologia da Universidade Federal do Maranhão - Campus Universitário - Bacanga - Bloco 3 - Sala 3A - 65.000 - São Luís, MA.
} 
BASTOS, O. de C. et al. Observações sobre os níveis glicêmicos de Holochilus brasiliensis nanus Thomas, 1897, hospedeiro natural do Schistosoma mansoni na Pré-Amazônia. Rev. Saúde públ., S. Paulo, 19:521-30, 1985.

(por volta de $20 \%$ ), como em hospedeiros não humanos ( 40 a $80 \%$, em roedores silvestres). A transmissão da doença na Baixada ocorre pelo contato do homem com águas contaminadas, tanto por lazer como por sobrevivência.

Entre animais que habitam naturalmente os lagos desta Região, encontra-se a Biomphalaria glabrata, hospedeira intermediária do verme, e roedores silvestres de várias espécies que se locomovem dentro d'água, por serem dotados de pequenas membranas interdigitais. Os Holochilus brasiliensis nanus é uma delas. Ao contraírem a infecção, constituem-se fonte de disseminação da doença na região, pelo fato do $S$. mansoni desenvolver-se, nestes animais, de forma semelhante ao homem.

Estudos sobre a anatomia-patológica e a imuno-patologia em Holochilus esquistossomóticos vêm sendo realizados no Programa de Imunologia da Universidade Federal do Maranhão4,5. Entretanto, não são conhecidos dados bioquímicos do sangue desses animais. Sabemos, entretanto, que o estado esquistossomótico modifica o equilíbrio metabólico do organismo do hospedeiro, seja ele humano ou animal, alterando-lhe as perspectivas de crescimento somático e ponderal, assim como sua capacidade reprodutiva ${ }^{6,12}$.

Com propósito de observar os efeitos bioquímicos decorrentes da infecção esquistossomótica em Holochilus brasiliensis nanus, que vem sendo oferecido como modelo experimental para esta parasitose, com mais eficiência do que os convencionais, e por ser hospedeiro definitivo natural do verme, avaliamos a evolução do seu estado glicêmico normal após infecção com $S$. mansoni.

\section{MATERIAL E METODOS}

2.1. Constituição de grupos de roedores silvestres para determinação da glicemia

Foram tomados 22 roedores silvestres, com idade de 30 a 40 dias de vida, nascidos no biotério da Universidade $\mathrm{Fe}$ deral do Maranhão.

Seus pesos corporais foram determinados e, em seguida, os roedores foram distribuídos em grupos, da seguinte forma:

Grupos:

Infectados com - 7 animais fêmeas, S. mansoni (GI) sendo 4 com 40 dias de vida e 3 com 30 .

Normais $\quad-15$ animais no to(Não infectados) tal, sendo que 7 deles (4 machos e 3 fêmeas) foram sangrados em jejum (GNJ), e os 8 restantes (4 machos e 4 fêmeas) foram sangrados sem estarem em jejum (GN).

\subsection{Infecção de roedores}

\subsubsection{Procedência do verme}

Biomphalaria glabrata, infectadas com S. mansoni, linhagem silvestre, da região da Baixada Maranhense ${ }^{3}$, foram expostas à luz e à temperatura de $28^{\circ} \mathrm{C}$, para eliminação de cercárias $S^{\theta}$. Estas larvas foram utilizadas para a infecção dos roedores.

\subsubsection{Método utilizado na infecção esquistossomótica}

Os roedores silvestres tiveram suas caudas submersas em uma suspensão cercariana (200 larvas por mililitro) ${ }^{2}$, em presença de luz e temperatura de $28^{\circ} \mathrm{C}$, 
BASTOS, O. de C. et al. Observações sobre os níveis glicêmicos de Holochilus brasiliensis nanus Thomas, 1897, hospedeiro natural do Schistosoma mansoni na Pré-Amazônia. Rev. Saúde públ., S. Paulo, 19:521-30, 1985.

por $2 \mathrm{~h}^{11}$. Em seguida os animais eram retirados desta condição laboratorial e mantidos em infectório até a data das sangrias.

\subsection{Dosagem de glicose}

\subsubsection{Obtenção do soro dos roedores}

Semanalmente, animais dos dois grupos eram pesados e sangrados pelo plexo venoso oftálmico. O sangue coletado era deixado em temperatura ambiente, para retração do coágulo, e o soro obtido era separado por centrifugação (400G, por $10 \mathrm{~min}$.

As sangrias eram feitas sempre no mesmo horário (às $12 \mathrm{~h}$ ).

\subsubsection{Método de dosagem}

As dosagens de glicose nos soros foram realizadas pelo método da Orto-Toluidina, uma vez que dentre os métodos colorimétricos utilizados para determinação da glicose, este é o mais aceito por serem obtidas medidas exatas até a absorbância de 0,900 , com precisão de \pm $5 \%$.

\subsection{Obtenção de vermes adultos}

Para obtenção de vermes adultos, os roedores silvestres, com mais de 8 semanas de infecção, foram anestesiados com éter e sacrificados. Os esquistossomos adultos foram coletados do fígado e plexo porta, de acordo com a técnica de perfusão de Yolles e col. ${ }^{13}$.

\section{RESULTADOS}

Os dados pertinentes a pesos corporais e dosagens de glicose determinadas nos grupos de animais normais e infectados estão apresentados em Tabelas.
3.1. Variações de pesos corporais de roedores

Animais nascidos em biotério, infectados com $S$. mansoni ou não, tiveram seus pesos previamente determinados, os quais se encontram expostos nas Tabelas 1,2 e 3.

Verifica-se que os animais normais ( $\mathrm{NJ}$ e $\mathrm{N}$ ) apresentaram aumento de pesos gradativos à sua maturação, independente de sexo. Os pesos pertinentes aos machos foram maior do que os das fêmeas (Tabela 1). Analisando a distribuição dos pesos em intervalos de $10 \mathrm{~g}$, constatou-se que esta distribuição foi normal.

Os roedores pertencentes a grupos de animais infectados (GI) comportaram-se da seguinte maneira: animais infectados aos 30 dias de vida apresentaram elevação de seus pesos médios, até a $6 .^{\mathrm{a}} \mathrm{se}$ mana de infecção, ocorrendo decréscimo em seus pesos, a partir desta data até a $8 .^{\text {a }}$ semana de observação, época em que ocorreu a morte de um dos elementos do grupo (Tabela 2). Animais infectados aos 40 dias de vida tiveram seus pesos em elevação até a última semana de trabalho (Tabela 3).

\subsection{Variações dos níveis glicêmicos}

Os diferentes níveis glicêmicos, obtidos das dosagens em soros dos roedores, estão tabelados. As quantificações referentes aos animais normais estão expostos na Tabela 4. Os resultados dos grupos dos roedores infectados estão descritos nas Tabelas 5 e 6 .

Analisando as curvas glicêmicas dos grupos de animais normais, dos dois sexos, com regime alimentar diferente, observa-se, em primeiro lugar, que as curvas apresentaram comportamentos parecidos. Segundo, que os perfis apresentaram uma deflexão aos 51 dias de idade, como se dividisse a curva em dois estados glicêmicos (Fig. 1). 
BASTOS, O. de C. et al. Observações sobre os níveis glicêmicos de Holochilus brasiliensis nanus Thomas, 1897, hospedeiro natural do Schistosoma mansoni na Pré-Amazônia. Rev. Saúde públ., S. Paulo, 19:521-30, 1985.

TABELA 1

Pesos corporais de roedores silvestres (Holochilus brasiliensis nanus), nascido em biotério, expresso em gramas, diferenciados por sexo e idade.

\begin{tabular}{|c|c|c|c|c|c|c|c|c|}
\hline \multirow{2}{*}{ Sexo } & \multicolumn{8}{|c|}{ Idade em dias } \\
\hline & 30 & 37 & 44 & 51 & 58 & 65 & 72 & 79 \\
\hline \multirow{7}{*}{ Fêmeas } & 49 & 53 & 59 & 73 & 68 & 74 & 81 & 85 \\
\hline & 47 & 53 & 62 & 76 & 72 & 82 & 94 & 102 \\
\hline & 60 & 73 & 85 & 155 & 104 & 119 & 127 & 135 \\
\hline & 72 & 80 & 83 & 93 & 105 & 109 & 112 & 128 \\
\hline & 74 & 89 & 94 & 105 & 115 & 115 & 120 & 132 \\
\hline & 65 & 71 & 74 & 74 & 86 & 86 & 93 & 103 \\
\hline & 79 & 90 & 91 & 99 & 114 & 116 & 121 & 130 \\
\hline$\overline{\mathbf{x}}$ & 64 & 73 & 78 & 96 & 95 & 100 & 104 & 116 \\
\hline$\sigma$ & 11 & 14 & 13 & 26 & 18 & 17 & 15 & 18 \\
\hline \multirow{8}{*}{ Machos } & 58 & 69 & 81 & 101 & 102 & 114 & 123 & 137 \\
\hline & 63 & 79 & 99 & 126 & 127 & 138 & 149 & 166 \\
\hline & 68 & 87 & 104 & 125 & 124 & 140 & 154 & 168 \\
\hline & 65 & 84 & 103 & 137 & 141 & 164 & 179 & 203 \\
\hline & 55 & 92 & 108 & 112 & 144 & 154 & 172 & 176 \\
\hline & 59 & 98 & 101 & 102 & 115 & 121 & 209 & 207 \\
\hline & 83 & 104 & 114 & 114 & 146 & 151 & 159 & 174 \\
\hline & 77 & 102 & 123 & 125 & 158 & 194 & 139 & 151 \\
\hline$\overline{\mathrm{X}}$ & 66 & 89 & 104 & 117 & 132 & 147 & 160 & 173 \\
\hline$\sigma$ & 09 & 11 & 11 & 12 & 17 & 23 & 24 & 22 \\
\hline
\end{tabular}

TABELA 2

Pesos corporais, expressos em gramas, determinados em Holochilus b. nanus, fêmeas, nascidas em biotério, infectadas com $S$. mansoni, aos 30 dias de vida.

\begin{tabular}{crrrrrrrr}
\hline \multirow{2}{*}{$\begin{array}{c}\text { Animal } \\
\text { N. }\end{array}$} & 37 & 44 & 51 & 58 & 65 & 72 & 79 & 86 \\
\cline { 2 - 9 } & 79 & 87 & 98 & 99 & 99 & 101 & 95 & Morte \\
\hline 1 & 90 & 101 & 106 & 107 & 117 & 117 & 108 & 101 \\
3 & 87 & 97 & 109 & 112 & 116 & 118 & 101 & 77 \\
\hline $\bar{X}$ & 85 & 95 & 104 & 106 & 110 & 112 & 101 & 89 \\
\hline$\sigma$ & 04 & 06 & 04 & 05 & 08 & 07 & 05 & 12 \\
\hline
\end{tabular}

$\overline{\mathrm{X}}$ - média aritmética

$\sigma$ - desvio padrão 
BASTOS, O. de C. et al. Observações sobre os níveis glicêmicos de Holochilus brasiliensis nanus Thomas, 1897, hospedeiro natural do Schistosoma mansoni na Pré-Amazônia. Rev. Saúde públ., S. Paulo, 19:521-30, 1985.

TABELA 3

Pesos corporais, expressos em gramas, determinados em Holochilus $b$. nanus, fêmeas nascidas em biotério, infectadas com $S$. mansoni, aos 40 dias de vida.

\begin{tabular}{crrrrrrrr}
\hline \multirow{2}{*}{$\begin{array}{c}\text { Animal } \\
\text { N. }\end{array}$} & \multicolumn{7}{c}{ Idade em dias } \\
\cline { 2 - 10 } & 47 & 54 & 61 & 68 & 75 & 82 & 89 & 96 \\
\hline 1 & 96 & 98 & 105 & 104 & 111 & 115 & 122 & 124 \\
2 & 124 & 125 & 126 & 130 & 138 & 139 & 145 & 155 \\
3 & 97 & 99 & 104 & 104 & 107 & 106 & 104 & 89 \\
4 & 109 & 112 & 126 & 125 & 132 & 137 & 142 & 149 \\
\hline $\bar{X}$ & 106 & 108 & 115 & 116 & 122 & 124 & 128 & 129 \\
\hline$\sigma$ & 11 & 11 & 10 & 12 & 13 & 14 & 16 & 26 \\
\hline
\end{tabular}

$\overline{\overline{\mathrm{X}}}$ - média aritmética $\quad \sigma$ - desvio padrão

\section{TABELA 4}

Níveis glicêmicos (mg\%) determinados em Holochilus b. nanus, não esquistossomóticos, diferenciados por sexo e condição alimentar, durante sua maturação.

\begin{tabular}{|c|c|c|c|c|c|c|c|c|}
\hline \multirow{2}{*}{$\begin{array}{l}\text { Condição } \\
\text { Alimentar }\end{array}$} & \multicolumn{8}{|c|}{ Idade em dias } \\
\hline & 30 & 37 & 44 & 51 & 58 & 65 & 72 & 79 \\
\hline 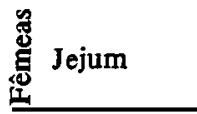 & $\begin{array}{l}178 \\
147 \\
207 \\
\end{array}$ & $\begin{array}{l}105 \\
105 \\
153 \\
\end{array}$ & $\begin{array}{l}171 \\
172 \\
237 \\
\end{array}$ & $\begin{array}{l}121 \\
136 \\
124 \\
\end{array}$ & $\begin{array}{l}104 \\
159 \\
230 \\
\end{array}$ & $\begin{array}{r}74 \\
122 \\
273 \\
\end{array}$ & $\begin{array}{l}133 \\
215 \\
235 \\
\end{array}$ & $\begin{array}{l}111 \\
192 \\
240 \\
\end{array}$ \\
\hline$\overline{\mathbf{X}}$ & 177 & 121 & 193 & 127 & 164 & 156 & 194 & 181 \\
\hline$\sigma$ & 24 & 22 & 31 & 06 & 51 & 85 & 44 & 53 \\
\hline Alimentados & $\begin{array}{l}211 \\
180 \\
241 \\
213 \\
\end{array}$ & $\begin{array}{l}198 \\
240 \\
212 \\
289\end{array}$ & $\begin{array}{l}192 \\
228 \\
250 \\
224 \\
\end{array}$ & $\begin{array}{l}136 \\
122 \\
128 \\
112\end{array}$ & $\begin{array}{l}238 \\
216 \\
240 \\
229\end{array}$ & $\begin{array}{l}203 \\
195 \\
195 \\
232 \\
\end{array}$ & $\begin{array}{l}205 \\
169 \\
212 \\
148\end{array}$ & $\begin{array}{l}199 \\
246 \\
246 \\
200 \\
\end{array}$ \\
\hline$\overline{\mathrm{X}}$ & 211 & 235 & 223 & 224 & 231 & 206 & 183 & 223 \\
\hline$\sigma$ & 21 & 35 & 21 & 09 & 09 & 15 & 26 & 23 \\
\hline 莺 Jejum & $\begin{array}{l}113 \\
115 \\
193 \\
107 \\
\end{array}$ & $\begin{array}{l}171 \\
145 \\
208 \\
164 \\
\end{array}$ & $\begin{array}{l}279 \\
246 \\
240 \\
284\end{array}$ & $\begin{array}{l}161 \\
211 \\
242 \\
268\end{array}$ & $\begin{array}{l}223 \\
240 \\
204 \\
241\end{array}$ & $\begin{array}{l}278 \\
200 \\
300 \\
315\end{array}$ & $\begin{array}{l}237 \\
282 \\
245 \\
321\end{array}$ & $\begin{array}{l}207 \\
207 \\
255 \\
354 \\
\end{array}$ \\
\hline$\overline{\mathrm{x}}$ & 132 & 172 & 262 & 220 & 227 & 273 & 271 & 256 \\
\hline$\sigma$ & 35 & 23 & 19 & 40 & 15 & 44 & 33 & 60 \\
\hline Alimentados & $\begin{array}{l}183 \\
184 \\
161 \\
249 \\
\end{array}$ & $\begin{array}{l}253 \\
239 \\
209 \\
320 \\
\end{array}$ & $\begin{array}{l}268 \\
294 \\
214 \\
305\end{array}$ & $\begin{array}{l}131 \\
165 \\
117 \\
165\end{array}$ & $\begin{array}{l}195 \\
303 \\
200 \\
249\end{array}$ & $\begin{array}{l}260 \\
293 \\
257 \\
254\end{array}$ & $\begin{array}{l}262 \\
312 \\
237 \\
256\end{array}$ & $\begin{array}{l}284 \\
288 \\
321 \\
283 \\
\end{array}$ \\
\hline$\overline{\mathrm{X}}$ & 194 & 255 & 270 & 144 & 237 & 266 & 267 & 294 \\
\hline$\sigma$ & 33 & 40 & 35 & 21 & 43 & 16 & 28 & 16 \\
\hline
\end{tabular}

$\overline{\bar{X}}$ - média aritmética $\sigma$ - desvio padrão 
BASTOS, O. de C. et al. Observações sobre os níveis glicêmicos de Holochilus brasiliensis nanus Thomas, 1897, hospedeiro natural do Schistosoma mansoni na Pré-Amazônia. Rev. Saúde públ., S. Paulo, 19:521-30, 1985.

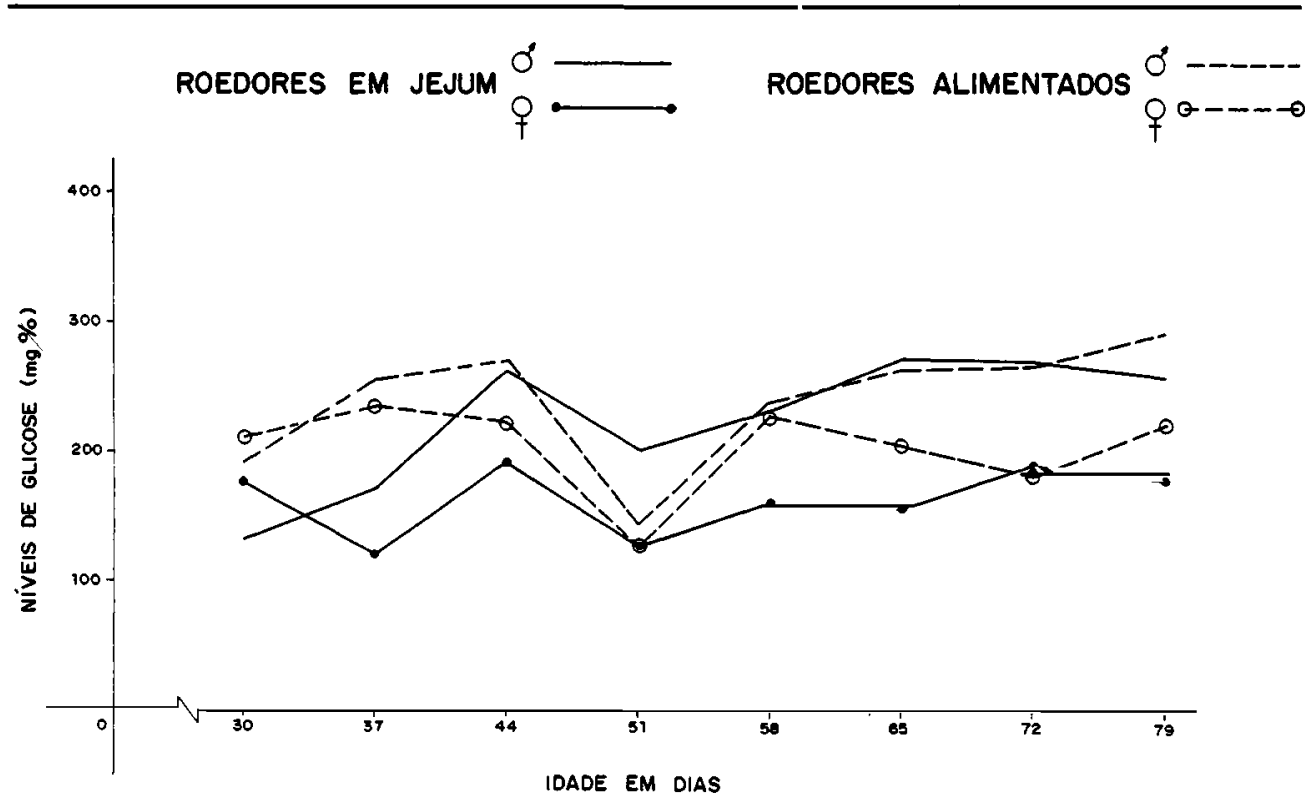

Fig. 1 - Niveis de glicose $(\mathrm{mg} / \%$ ) encontrados em soro de Holochilus b. nanus, nascidos em biotério, determinados com ou sem regime alimentar, nos dois sexos, e diferenciados por idade, expressa em dias.

Os níveis glicêmicos encontrados no grupo de animais fêmeas foram mais baixos do que o grupo de animais machos.

Os dados da glicemia obtida no gru- po de animais infectados com $S$. mansoni, aos 30 e 40 dias, foram diferentes dos resultados encontrados nos grupos de animais normais. Ocorreram diferenças quanto aos perfís e concentrações

TABELA 5

Níveis glicêmicos (mg\%) determinados em Holochilus b. nanus, fêmeas, nascidas em biotério, infectadas com $S$. mansoni, aos 30 dias de vida

\begin{tabular}{crrrrrrrr}
\hline \multirow{2}{*}{$\begin{array}{c}\text { Animal } \\
\text { N. }\end{array}$} & 37 & 44 & 51 & 58 & 65 & 72 & 79 & 86 \\
\cline { 2 - 9 } & 211 & 188 & 165 & 210 & 210 & 144 & 105 & 86 \\
1 & 203 & 251 & 222 & 163 & 192 & 155 & 193 & 148 \\
2 & 200 & 209 & 162 & 160 & 151 & 92 & 157 & 73 \\
3 & 204 & 216 & 183 & 177 & 184 & 130 & 151 & 102 \\
\hline $\bar{X}$ & 04 & 26 & 27 & 23 & 24 & 27 & 36 & 33 \\
\hline$\sigma$ & & & & &
\end{tabular}

$\overline{\bar{X}}$ - média aritmética $\quad \sigma$ - desvio padrão

de glicose. Os níveis glicêmicos dos animais esquistossomóticos foram mais estáveis e com valores menores do que os encontrados nos animais normais. Notificamos uma leve depressão da curva dos infectados, após os 70 dias de vida, ou seja, mais tardiamente, em relação aos normais.

O perfil geral destes dados mostranos que os animais infectados aos 30 
BASTOS, O. de C. et al. Observações sobre os níveis glicêmicos de Holochilus brasiliensis nanus Thomas, 1897, hospedeiro natural do Schisiosoma mansoni na Pré-Amazônia. Rev. Saúde públ., S. Paulo, 19:521-30, 1985.

dias tiveram seus níveis glicêmicos em declínio à proporção que a infecção evoluia; enquanto que os animais infectados aos 40 dias de vida tiveram seus níveis de glicose, durante as 8 semanas de infecção, sem diferença significativa entre eles (Fig. 2).

\subsection{Número de vermes adultos}

O número dos vermes adultos recuperados dos animais infectados está transcrito na Tabela 7.

ROEDORES INFECTADOS AOS 30 DIAS

ROEDORES INFECTADOS AOS 40 DIAS

0

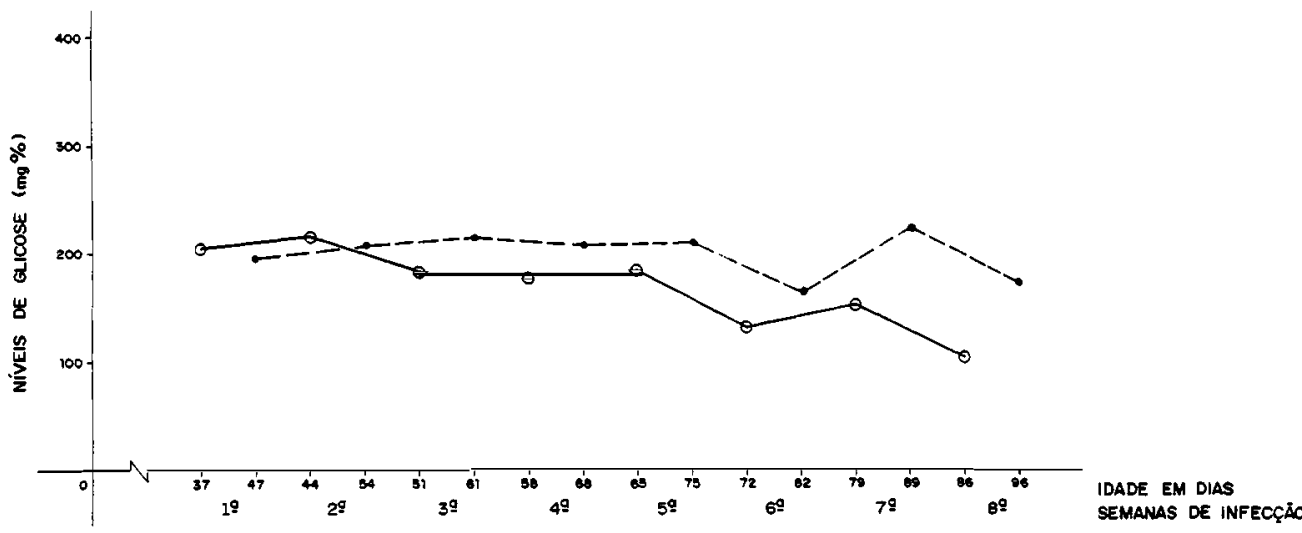

Fig. 2 - Niveis de glicose $(\mathrm{mg} / \%)$ encontrados em Holochilus b. nanus, infectados, aos 30 e 40 dias de vida, com Schistosoma mansoni, determinados semanalmente.

TABELA 6

Níveis glicêmicos (mg\%) determinados em Holochilus b. nanus, fêmeas, nascidas em biotério, aos 40 dias de vida.

\begin{tabular}{lcccccccc}
\hline \multirow{2}{*}{$\begin{array}{c}\text { Animal } \\
\text { N. }\end{array}$} & 47 & 54 & 61 & 68 & 75 & 82 & 89 & 96 \\
\cline { 2 - 9 } & 190 & 227 & 237 & 204 & 189 & 163 & 234 & 139 \\
1 & 213 & 206 & 219 & 199 & 225 & 210 & 247 & 239 \\
2 & 202 & 194 & 219 & 220 & 192 & 120 & 190 & 118 \\
3 & 189 & 211 & 189 & 198 & 235 & 165 & 226 & 207 \\
4 & 198 & 209 & 216 & 205 & 210 & 164 & 224 & 175 \\
\hline $\bar{X}$ & 10 & 12 & 17 & 09 & 20 & 32 & 21 & 49 \\
\hline$\sigma$ & & & & & & 210 \\
\hline
\end{tabular}

$\overline{\mathbf{X}}$ - média aritmética

$\sigma$ - desvio padrão 
BASTOS, O. de C. et al. Observações sobre os níveis glicêmicos de Holochilus brasiliensis nanus Thomas, 1897, hospedeiro natural do Schistosoma mansoni na Pré-Amazônia. Rev. Saúde públ., S. Paulo, 19:521-30, 1985.

\section{TABELA 7}

Número de vermes obtidos de roedores silvestres, em diferentes idades, fêmeas, com 8 semanas de infecção com $S$. mansoni.

\begin{tabular}{|c|c|c|c|}
\hline \multirow{2}{*}{$\begin{array}{c}\text { Idade de } \\
\text { infecção } \\
\text { (dias) }\end{array}$} & \multirow{2}{*}{$\underset{\text { N. }}{\text { Animal }}$} & \multicolumn{2}{|c|}{ Esquistossomos } \\
\hline & & Machos & Fêmeas \\
\hline \multirow[t]{2}{*}{30} & $1^{*}$ & 一 & - \\
\hline & $\begin{array}{l}2 \\
3 \\
\end{array}$ & $\begin{array}{l}34 \\
23\end{array}$ & $\begin{array}{l}30 \\
22\end{array}$ \\
\hline \multicolumn{2}{|l|}{ Total } & 57 & 52 \\
\hline 40 & $\begin{array}{l}1 \\
2 \\
3 \\
4 \\
\end{array}$ & $\begin{array}{l}09 \\
05 \\
18 \\
06\end{array}$ & $\begin{array}{l}09 \\
05 \\
19 \\
06\end{array}$ \\
\hline Total & & 38 & 39 \\
\hline
\end{tabular}

* Animal que morreu antes da data do sa. crifício.

\section{DISCUSSÃO E CONCLUSAOO}

O método da Orto-Toluidina, embora seja capaz de reagir com a galactose em reação cruzada, ainda se constitui no melhor método não enzimático para dosar fielmente a glicose verdadeira.

A praticidade do método torna-o acessível e nos possibilita obter resultados antes de duas horas. Isto é importante, uma vez que a glicose é degradada no soro coletado, a cada hora, de 10 a $20 \%$ dos seus níveis normais.

Os animais tomados para experiência tiveram seus pesos corporais dentro de uma distribuição normal (Tabela 1). A elevação destes pesos, durante o período em que se realizou o trabalho, resultou da evolução natural dos animais.

A esquistossomose influiu no crescimento normal dos roedores, haja vista que os pesos dos infectados não acompanharam a ascendência da curva dos normais (Tabelas 2 e 3). A confirmação deste fenômeno pode ser verificada entre os animais infectados, aos 30 e 40 dias de vida, e os animais normais.

Os animais parasitados aos 30 dias apresentaram debilitação geral, com redução de seus pesos, a partir da $6 .^{a}$ semana de infecção; e comportamento diferente dos infectados aos 40 dias, que mantiveram seus pesos médios constantes, a partir desta data.

Analisando os valores individuais dos níveis glicêmicos próprios dos animais normais, dos dois sexos e com regime alimentar distintos (Tabela 4), constatamos maior heterogeneidade nos dados pertinentes aos machos e estabilidade nas concentrações glicêmicas das fêmeas, o que nos motivou a infectar animais fêmeas, com vista a verificarmos a influência da parasitose sobre estes níveis.

Os perfis glicêmicos dos animais infectados, que diferiram quanto à idade, na data da infecção (Fig. 2), podem ser discutidos da seguinte forma: os animais infectados aos 30 dias de vida foram mais suscetíveis à infecção com $S$. mansoni, uma vez que mostraram sensível queda na curva glicêmica; e maior número de vermes e caso de morte, pela parasitose, quando comparados com os dados dos roedores expostos ao $S$. mansoni aos 40 dias de vida. Acreditamos que estas diversidades de comportamento se deva ao comprometimento dos órgãos, como fígado, baço e pâncreas, pelo processo parasitário. Ocorrências semelhantes foram vistas no próprio roedor, quando estudado sob o ponto de vista patológicos e em outros animais utilizados como modelo experimental, com destaque ao camundongo ${ }^{8}$. Portanto, a idade de 30 dias é a ideal para o estudo do comportamento parasita-hospedeiro em roedores silvestre. 
BASTOS, O. de C. et al. Observações sobre os niveis glicêmicos de Holochilus brasiliensis nanus Thomas, 1897, hospedeiro natural do Schistosoma mansoni na Pré-Amazônia. Rev. Saúde públ., S. Paulo, 19:521-30, 1985.

BASTOS, $O$. de $C$. et al. [Observations on glicemic levels of Holochilus brasiliensis nanus Thomas, 1897, natural host of Schistosoma mansoni from lower Amazonia] Rev. Saúde públ., S. Paulo, 19 :521-30, 1985.

ABSTRACT: Laboratory-reared wild rodents descended from Holochilus b. nanus and captured in the lowland region of lower Amazonia, were experimentally infected with Schistosoma mansoni from the same region in order to verify the influence of the infection on glicemic levels. A normal rodent group was also investigated in order to ascertain the normal glucose serum levels. Both groups (normal and infected animals) were carefully differentiated according to sex, alimentary regime and infection time. The bleeding was done weekly in the ophtalmic plexus, and always at the same scheduled time. The glucose was quantified by means of the Ortho-Toluidin method. The results showed body-weight increase in every normal animal during this maturation, the infected animals showed weight decrease along with the development of the infection. The normal female animals had lower and more stable glucose levels, than the males, whether fed or not. In the 30-day-old infected animals the glucose levels declined as the infection developed (because it may be supposed, of the way the organs such as the liver, the spleen and the pancreas were affected). The glucose levels in the 40-day-old infected animals, during the 8 weeks of infection, did not vary significantly. The number of adult worms recovered from the 30-day-old infected animals were greater than from the other group. The data also showed that the ideal age for infection in this experimental model was at $\mathbf{3 0}$ days of life, similar to that of others, such as mice.

UNITERMS: Holochilus brasiliensis nanus, experimental infection. Schistosoma mansoni. Blood glicose, analyses.

\section{REFERENCIAS BIBLIOGRAFICAS}

1. ALVIM, M. de C. A esquistossomose no Maranhão. Hiléia méd., Belém, 2: 151. $7,1980$.

2. BARRIOS-DURAN, L. A. An eficient device for exposing mice to Schistosomo cercariae and holding small animal for port-morten examination. J. Parasit. 41: 641-2, 1955.

3. BASTOS, O. de C.; SILVA, A . M. A.; SOUZA, E. P. de; LEMOS NETO, R. C. \& PIEDRABUENA, A. E. Ocorrência de linhagens humana e silvestre de Schistosoma mansoni, na pré-amazônia. I - Estudo em molusco. Rev Saúde publ., S. Paulo, 16: 292-8, 1982.

4. BASTOS, O. de C.; BRITTO, M. H. S. S.; SCHIAVOTELO, M. S. S. \& SOUZA, E. P. de. Variações dos níveis do componente $\mathrm{C}_{3}$ do complemento em Holochilus brasiliensis nanus experimentalmente infectados com Schistosoma mansoni. Rev. Saúde públ., S. Paulo, 18: 41-6, 1984.

5. BASTOS, O. de C.; SADIGURSKY, M.; NASCIMENTO, M. do D. S. B.; BRA-
ZIL, R. P. \& HOLANDA, J. C. Holochilus brasiliensis nanus Thomas, 1897. Sugestão de modelo experimental para filariose, leishmaniose e esquistossomose. Rev. Inst. Med. trop. S. Paulo, 26: 307-15, 1984.

6. COSTA, J. de S.; DIAS, C. N.; BURGOS, $M$. da P. P.; TRINDADE, F. \& COSTA, O. L. N. Perturbações endócrinas na esquistossomose. Aspectos experimentais da esquistossomose hepatesplênica em camundongos. Rev. Inst. Med. trop. S. Paulo, 22: 246-60, 1980.

7. CUNHA, A. S. da. Esquistossomose mansoni. São Paulo, Sarvier, 1970.

8. KENNETH, S. W. The immunopatogenesis of schistosomiasis: a multidisciplinary approach. Trans. roy. Soc. trop. Med. Hyg., 66: 417-31, 1972.

9. Pellegrino, J. \& MACEDO, D. G. A simplified method for concentration of cercariae. J. Parasit. 41: 329-30, 1955.

10. PESSOA, S. B. \& MARTINS, A. V. Parasitologia médica. Rio de Janeiro, Guanabara Koogan, 1982. 
BASTOS, O. de C. et al. Observações sobre os níveis glicêmicos de Holochilus brasiliensis nanus Thomas, 1897, hospedeiro natural do Schistosoma mansoni na Pré-Amazônia. Rev. Saúde públ., S. Paulo, 19:521-30, 1985.

11. STANDEN, O. D. Experimental infection of Australorbis with S. mansoni. I - Individual and mass infection to temperature and sesan. Ann. trop. Med. Pa. rasit., 46: 48-53, 1952.

12. SUCUPIRA, M. S. \& PUPO, A. de A. Estudos hormonais do hipodesenvolvimento somático e puberal de portadores de esquistossomose mansônica. Rev. Ass. med. bras., S. Paulo, 22: 154-61, 1976.
13. YOLLES, T.; MOORE, D.; DE FINST, D. L.; RIPSON, C. A. \& MELENEY, H. E. A technique for the perfusion of laboratory animals for the recovery of schistosomos. J. Parasit. 33: 419-26, 1947.

Recebido para publicação em 01/03/1985

Reapresentado em 24/06/1985

Aprovado para publicação em 02/07/1985 